Indones J

\title{
Editorial
}

\section{The Role of Gynecologists in Managing Endometrial Cancer}

\author{
Sigit Purbadi
}

Endometrial cancer is the most common female cancer in developed countries. In Indonesia, cervical cancer is the fourth most common cancer after cervical cancer, ovarian cancer and malignant trophoblastic disease.* Geographic condition and limited number of gynecologic oncologists are associated with patients access in oncologic services.

Can gynecologist manage endometrial cancer? This is a common question from patients because there are many cases of inadequate treatment for endometrial cancer. Gynecologists should be competent enough to diagnose endometrial cancer to guide treatment for the patients properly. Finally, gynecologists should be competent to treat endometrial cancer in selective patients.

Base on histopathology, endometrial cancer divided into two types. Type 1 is related to unopposed estrogen, and the histopathology is endometrioid adenocarcinoma. This type generally is low-grade. Type II is mostly high-grade or has histopathology as papillary serous adenocarcinoma or clear cell carcinoma. This grouping is crucial because the gynecologist only allowed to manage the low-risk group; it means the histopathology must be type I and clinically stage 1A. The reason why gynecologist did not have any competency to manage type II endometrial cancer because surgical management is different; its surgical staging included pelvic and paraaortic lymphadenectomy. This competency was not stated in the curriculum.

How to diagnose endometrial cancer? The procedure can be started from clinical and imaging examination to evaluate the tumour mass, including the invasiveness of endometrial cancer. This invasiveness can be determined by using ultrasonography examination, computed tomography scan and magnetic resonance imaging. ${ }^{2}$ The golden standard for diagnosingendometrial cancer ishistopathological examination. The specimen for histopathology could be taken from endometrial biopsy or curettage. Biopsy-guided hysteroscopy is an optional procedure in endometrial cancer in Indonesia. However, it is recommended in the United States of America. ${ }^{2-4}$ One critical point is that gynaecologist must be competent to diagnose endometrial cancer based on histopathological examination as type 1 and from an image is stage $1 \mathrm{~A}$, because only stage $1 \mathrm{~A}$ endometrial cancer stage and well-differentiated endometrioid adenocarcinoma are allowed to betreated by gynecologists. The management includes fertility-sparing procedure or other surgical procedures. These competencies are stated in the curriculum of Obstetrics and Gynecology speciality program education. The clue of fertility-sparing management in endometrial cancer should be based on the basic concept of endometrial cell proliferation and cell cycle arrest. Several hormones which have anti-proliferation is a modality for fertility-sparing management. ${ }^{4-6}$ Surgical management for low-risk endometrial cancer can be managed by hysterectomy with or without bilateral salpingo-oophorectomy. Therefore, every education centre must train obstetrics and gynecology residents adequately. The Indonesian Obstetrics and Gynecology College is responsible for making this policy, including quality control in this process of training, which is this point stated in the logbook. Hopefully, for the next decade, endometrial cancer will be managedadequately.

*Indonesia Pathology Base Cancer Report 2015 


\section{REFERENCES}

1. Clinical SGO, Endometrial P, Working C, Burke WM, Orr J, Leitao M, et al. Gynecologic Oncology Endometrial cancer : A review and current management strategies : Part II. Gynecol Oncol [Internet]. 2014;134(2):393-402. Available from: http://dx.doi.org/10.1016/j.ygyno.2014.06.003

2. Braun MM, Army M, Overbeek-wager WEA, Army E, Hospital C, Carson F, et al. Diagnosis and Management of Endometrial Cancer. Am Fam Physician. 2016; 93(6):468-74.

3. Clinical SGO, Endometrial P, Working C, Burke WM, Orr J, Leitao M, et al. Gynecologic Oncology Endometrial cancer : A review and current management strategies : Part I. Gynecol Oncol [Internet]. 2014;134(2):385-92. Available from: http://dx.doi.org/10.1016/j.ygyno.2014.05.018

4. Colombo N, Creutzberg C, Amant F, Bosse T, González-Martín A, Ledermann J, et al. ESMO-ESGO-ESTRO consensus conference on endometrial cancer: Diagnosis, treatment and follow-up. Radiother Oncol. 2015;117(3):559-81.

5. Lu KH. Management of Early-Stage Endometrial Cancer. 2009;36(2):137-44.

6. Tock S, Jadoul P, Squifflet J, Marbaix E. Fertility Sparing Treatment in Patients With Early Stage Endometrial Cancer, Using a Combination of Surgery and GnRH Agonist : A Monocentric Retrospective Study and Review of the Literature. 2018;5:1-10. 